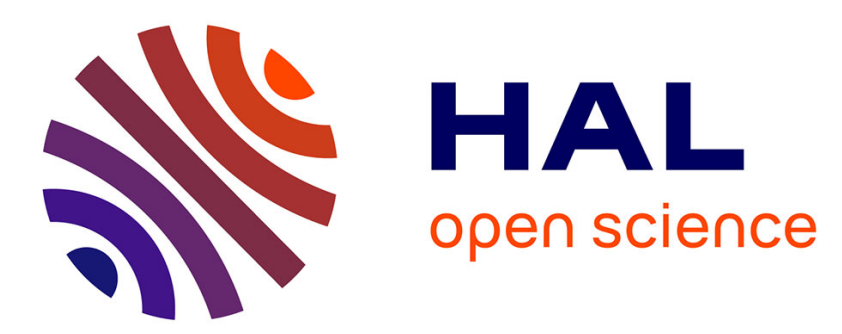

\title{
On the use of spray systems: an example of r\&d work in hydrogen safety for nuclear applications
}

Coralie Joseph-Auguste, Homan Cheikhravat, Nabiha Chaumeix, Enrico Deri

\section{To cite this version:}

Coralie Joseph-Auguste, Homan Cheikhravat, Nabiha Chaumeix, Enrico Deri. On the use of spray systems: an example of $r \& d$ work in hydrogen safety for nuclear applications. International Journal of Hydrogen Energy, 2009, pp.1. 10.1016/j.ijhydene.2009.01.018 . hal-00362596

\section{HAL Id: hal-00362596 https://hal.science/hal-00362596}

Submitted on 23 Feb 2009

HAL is a multi-disciplinary open access archive for the deposit and dissemination of scientific research documents, whether they are published or not. The documents may come from teaching and research institutions in France or abroad, or from public or private research centers.
L'archive ouverte pluridisciplinaire HAL, est destinée au dépôt et à la diffusion de documents scientifiques de niveau recherche, publiés ou non, émanant des établissements d'enseignement et de recherche français ou étrangers, des laboratoires publics ou privés. 


\title{
ON THE USE OF SPRAY SYSTEMS: AN EXAMPLE OF R\&D WORK IN HYDROGEN SAFETY FOR NUCLEAR APPLICATIONS
}

\author{
Coralie Joseph-Auguste ${ }^{1, *}$, Homan Cheikhravat ${ }^{2}$, Nabiha Djebaïli-Chaumeix ${ }^{3}$, Enrico Deri ${ }^{1}$ \\ ${ }^{1}$ Commissariat à l'Energie Atomique, CEA Saclay, DEN/DM2S/SFME, 91191 Gif-sur-Yvette Cedex, \\ France \\ ${ }^{2}$ Institut de Radioprotection et de sûreté nucléaire, BP 17, 92262 Fontenay aux Roses, France \\ ${ }^{3}$ Institut de Combustion, Aérothermie, Réactivité et Environnement, CNRS-Orléans, France
}

\begin{abstract}
In this manuscript a simple Lumped Parameter model, developed in order to study the interaction between water droplets and a hydrogen-air flame, has been presented. A parametric study has been described and the results given by the proposed model are discussed in the paper. In addition, the description of an experimental facility designed to study these thermodynamics aspects is reported here. In particular, the nozzles of the spray system of the facility has been characterized in terms of drop size distribution. (2008)

Keywords: Hydrogen risk analysis; Hydrogen combustion; Water spray; Lumped Parameter analysis

\section{Nomenclature}

$\begin{array}{lll}\text { Symbols } & \text { Descriptions } & \text { Units } \\ f_{V} & \text { Volume fraction of liquid water } & - \\ h_{0}^{s} & \text { Sensible enthalpy } & \mathrm{J} \cdot \mathrm{kg}^{-1} \\ \Delta h_{0} & \text { Formation mass enthalpy at the reference temperature } \mathrm{T}=0 \mathrm{~K} & \mathrm{~J} \cdot \mathrm{kg}^{-1} \\ m & \text { Mass } & \mathrm{kg} \\ n & \text { Number of moles } & \mathrm{mol} \\ p & \text { Pressure } & \mathrm{Pa} \\ T & \text { Temperature } & \mathrm{K} \\ R_{j} & \text { j - gas constant } & \mathrm{J} \cdot \mathrm{kg}^{-1} \cdot \mathrm{K}^{-1} \\ R & \text { Perfect gas constant }(\approx 8.313) & \mathrm{J} \cdot \mathrm{mol}^{-1} \cdot \mathrm{K}^{-1} \\ S & \text { Number of species in the gaseous phase } & - \\ u & \text { Velocity } & \mathrm{m} \cdot \mathrm{s}^{-1} \\ v & \text { Diffusion velocity } & \mathrm{m} \cdot \mathrm{s}^{-1} \\ \text { V } & \text { Volume } & \mathrm{m}^{3} \\ W & \text { Molar mass } & \mathrm{kg} \cdot \mathrm{mol}^{-1}\end{array}$
\end{abstract}

\footnotetext{
Corresponding author. Tel.: +33 169087084; fax: +33 169088229. E-mail address: coralie.josephauguste@cea.fr (C. Joseph-Auguste)
} 


\begin{tabular}{|c|c|}
\hline $\mathrm{x}_{\mathrm{j}}$ & Mole fraction of the $\mathrm{j}$ species \\
\hline $\mathrm{y}_{\mathrm{j}}$ & Mass fraction of the $\mathrm{j}$ species \\
\hline \multicolumn{2}{|l|}{ Greek } \\
\hline$\varepsilon$ & Specific internal energy \\
\hline$\rho$ & Density \\
\hline \multicolumn{2}{|c|}{ Subscripts } \\
\hline air & Refers to air \\
\hline fin & Refers to final state \\
\hline gas & Refers to gas \\
\hline $\mathrm{H} 2$ & Refers to hydrogen \\
\hline $\mathrm{H} 2 \mathrm{O}$ & Refers to steam \\
\hline init & Refers to initial state \\
\hline $\mathrm{j}$ & Refers to j-species \\
\hline liq & Refers to liquid water \\
\hline $\mathrm{N} 2$ & Refers to nitrogen \\
\hline $\mathrm{O} 2$ & Refers to oxygen \\
\hline tot & Refers to total quantity \\
\hline vap & Refers to vapor \\
\hline \multicolumn{2}{|c|}{ Superscripts } \\
\hline AICC & Refers to Adiabatic Isochoric Complete Combustion states \\
\hline comb & Refers to combustion \\
\hline evap & Refers to vaporization \\
\hline fin & Refers to final \\
\hline init & Refers to initial \\
\hline
\end{tabular}

\section{Introduction}

A considerable effort in hydrogen safety R\&D has occurred since the Three Mile Island nuclear accident in 1979 through experimental programs and computational tools development for a better understanding of hydrogen release, distribution and possible combustion regimes. As a result of this work, different types of mitigation systems such as recombiners, igniters and spray systems have been designed and installed in modern nuclear power plants. Mitigation systems related to hydrogen safety in nuclear power plants have been the subject of several experimental and theoretical/computational studies in the past. In French Pressurized Water Reactors, water spray systems have been designed in order to reduce overpressures in the containment and to remove from the atmosphere of this containment any scattered radioactive aerosols in the case of loss of coolant accident (LOCA). Although the presence of a cloud of water droplets can generate flammable mixtures or would enhance flame propagation through turbulence in the case of steam inerted air-hydrogen mixtures, beneficial effects would be heat sinks and mixtures homogenization. The combustion of gaseous mixtures of hydrogen-air (diluted or not) has been the subject of many studies both in the case of laminar and turbulent regimes (see [1,2] and references therein). However, in case where droplets of water are present no experimental data were found in the literature and the different mechanisms involved are not well described there. In this work, two objectives are defined, the first one is to study the thermodynamics aspects via a Lumped Parameter analysis and the interaction of a laminar premixed air-hydrogen-steam flame with a water mist via a CFD analysis. Only the Lumped Parameter analysis 
is described in this paper. The numerical results are obtained with Cast3M/TONUS [3], a freely available code developed at the French Atomic Energy Commission (CEA). This code solves the differential partial equations of fluid and solid mechanics using finite element and finite volume methods. The second one is to investigate experimentally the interaction of the flame with water droplets in the case where the flame is initially laminar.

\section{Lumped Parameter analysis: hydrogen combustion under liquid water conditions}

The main mechanisms involved in a flame and a water spray interaction are identified: heat transfer between the flame front and the spray, momentum transfer (drag force, transport of droplets) and mass transfer (vaporization). The heat transfer mechanisms between a methane-air flame front and a water spray or mist have been fully described by Parra et al [4]. Besides the flame extinction mechanisms [5,2,6] and the mitigation effects of the spray [7-13] are characterized for methane- or propane-air flame. The fine analysis of the above topics is very limited in the literature and some discrepancies are observed between the experimental data and numerical results. The results of Proust [14] showed that the theories of Mitani [15] for a methane-air flame might be improved by integrating the following phenomena: the variation of the "thermal" parameters with the temperature, a more detailed chemical reaction mechanism, the incidence of the radiation by the burnt products and the influence of the water droplets size distribution. However the interaction between water droplets and a hydrogen-air flame inerted by steam is not well described. In the case of steam inerted air-hydrogen mixture, the presence of water droplets can generate flammable mixtures or enhance flame propagation through turbulence $[11,16]$. Yet beneficial effects would be heat sinks and homogenization of mixtures.

\subsection{Lumped Parameter model}

A Lumped Parameter model has been developed in the Cast3M/TONUS code in order to study the thermodynamic aspects involved in the interaction between water droplets and a hydrogen-air flame. This asymptotic analysis simply allows us to find the final state of the system. That is why the chemical kinetics are not accounted for and the code does not calculate any reaction rates. The results will be used to validate the equilibrium states of a CFD analysis currently in progress. We consider an air-hydrogen-steam mixture and an amount of liquid water in a confined space. At this stage, the gases and droplets speeds and the size of droplets are not taken into account. The energy released by the reaction air-hydrogen vaporizes the liquid water.

Although the Lumped Parameter analysis is based on the hydrogen progress variable, i.e. it takes into account an incomplete combustion by considering the ratio between the burnt hydrogen number of moles over the initial ones, this study will focus on complete combustion.

The hypotheses we take into account in this work are summarized in figure 1:

1) conservation of mass and energy (impermeable and adiabatic walls),

2) the gases are considered as ideal gases,

3) the volume is constant,

4) the combustion is complete,

5) the whole energy liberated by the combustion vaporizes the liquid water,

6) air is considered as a binary mixture $\left(\mathrm{N}_{2}-\mathrm{O}_{2}\right)$,

7) hydrogen combustion is a single-step reaction and 
8) the gaseous mixture is initially at $T_{0, \text { gas }}=413.15 \mathrm{~K}$ and the liquid water at $T_{0, \text { liq }}=298.15 \mathrm{~K}$.

We compute the final species number of moles using the initial data and the above mentioned hypotheses.

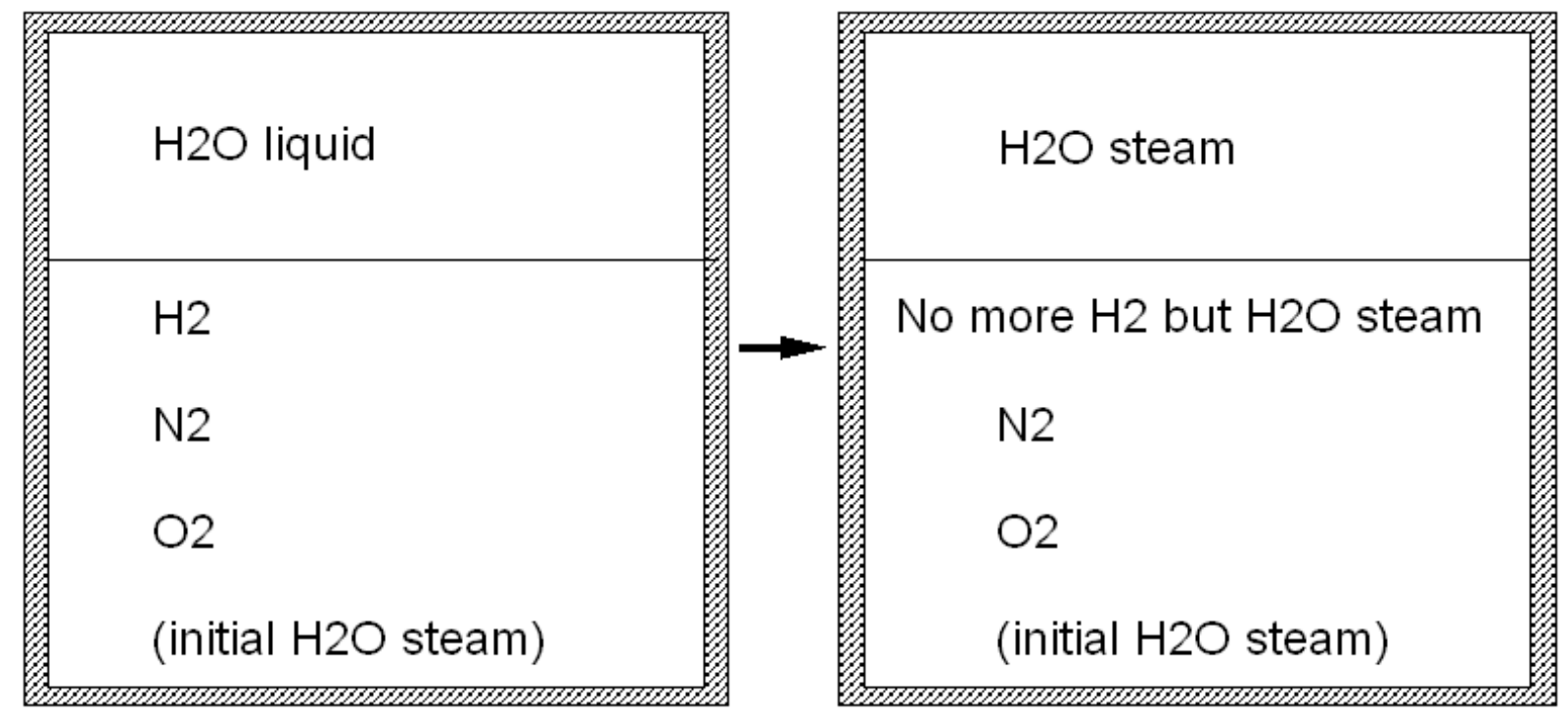

Figure 1. The species before and after combustion

As we assume that the combustion reaction is complete and single-step and the mixture is lean or stoichiometric,

$n_{H_{2}}^{\text {fin }}=0$,

$n_{\mathrm{H}_{2} \mathrm{O}^{\text {comb }}}^{\text {fin }}=n_{\mathrm{H}_{2}}^{\text {ini }}+n_{\mathrm{H}_{2} \mathrm{O}_{\text {vap }}}^{\text {ini }}$,

$n_{O_{2}}^{f i n}=n_{O_{2}}^{i n i}-\left(\frac{1}{2} n_{H_{2}}^{i n i}\right)$ and

$n_{N_{2}}^{\text {fin }}=n_{N_{2}}^{i n i}$

Besides, the whole liquid water is supposed to evaporate so that $n_{\mathrm{H}_{2} \mathrm{O}^{\text {evap }}}^{\text {fin }}=n_{\mathrm{H}_{2} \mathrm{O}_{\text {liq }}}^{\text {ini }}$. The initial number of moles of liquid water is defined by: $n_{\mathrm{H}_{2} \mathrm{O}_{\text {liq }}}^{i n i}=\frac{\rho_{\mathrm{H}_{2} \mathrm{O}} \cdot f_{V} \cdot V_{\text {tot }}}{W_{\mathrm{H}_{2} \mathrm{O}}}$ where $f_{V}$ is the initial volume fraction of liquid water. The energy released by the air-hydrogen reaction is computed using the CHEMKIN coefficients [17]. The initial values for pressure $p_{0}$ and steam mole fraction $x_{\mathrm{H}_{2} \mathrm{O}}^{\text {init }}$ in this study are equal to $1 \mathrm{~atm}\left(1.01310^{5} \mathrm{~Pa}\right)$ and zero (no steam before combustion), respectively.

The computation is divided into several steps: 
calculation of amount of energy released due to complete combustion

$$
\begin{aligned}
& f_{\text {gas }}\left(T_{\text {fin }}\right)=m_{\text {gas }}^{\text {init }} \cdot\left[-\left(h_{0}^{s}\left(T_{0, \text { gas }}\right)-R^{\text {init }} \cdot T_{0, \text { gas }}+\Delta h_{0}^{\text {init }}\right)+\left(h_{0}^{s}\left(T_{\text {fin }}\right)-R^{\text {fin }} \cdot T_{\text {fin }}+\Delta h_{0}^{\text {fin }}\right)\right] \\
& =\Delta\left(m_{\text {air }} \varepsilon_{\text {air }}+m_{\mathrm{H}_{2}} \varepsilon_{\mathrm{H}_{2}}+m_{\text {vap }} \varepsilon_{\text {vap }}\right)
\end{aligned}
$$

where $R^{\text {init }}=\sum_{j} R_{j} y_{j}^{\text {init }}, R^{\text {fin }}=\sum_{j} R_{j} y_{j}^{\text {fin }}$ (the steam provided by the vaporization of liquid water is not taken into account here), $R_{j}$ is the ideal gas constant for the $\mathrm{j}$ species, $m$ the mass, $\varepsilon$ the internal energy, $h_{0}^{s}$ the mixture sensible enthalpy $\left(\mathrm{J}^{\mathrm{kg}} \mathrm{kg}^{-1}\right)$ and $\Delta h_{0}$ the formation enthalpy. The system is closed because it does not exchange any matter with its surroundings: the hydrogen and oxygen masses decrease while the water vapor mass increases during the combustion reaction;

calculation of amount of energy necessary to heat and evaporate liquid water and to heat the resulting steam

$$
f_{\text {liq }}\left(T_{\text {fin }}\right)=m_{\text {liq }}^{\text {init }} \cdot\left(\left[\varepsilon_{\text {liq }}\left(T_{\text {sat }}, p_{0, \text { gas }}\right)-\varepsilon_{\text {liq }}\left(T_{0, l i q}, p_{0, g a s}\right)\right]+\left[\varepsilon_{\text {vap }}\left(T_{\text {sat }}\right)-\varepsilon_{\text {liq }}\left(T_{\text {sat }}, p_{0, g a s}\right)\right]+\left[\varepsilon_{\text {vap }}\left(T_{\text {fin }}\right)-\varepsilon_{\text {vap }}\left(T_{\text {sat }}\right)\right]\right)
$$

It should be recalled that the gases are supposed ideal (see hypothesis number 2 before figure 1);

under the hypothesis of final thermal equilibrium, we solve the following equation $f_{\text {gas }}\left(T_{\text {fin }}\right)=f_{\text {liq }}\left(T_{\text {fin }}\right)$ with the final temperature $T_{\text {fin }}$ as unknown;

calculation of the final density $\rho_{f i n}=\sum_{j=1}^{S} n_{j} W_{j} / V_{t o t}$, with $n_{j}$ the number of moles for the $\mathrm{j}$ species, $V_{\text {tot }}$ the total volume and $S$ the number of species in the gaseous phase;

calculation of the final pressure $p_{f i n}$ from the ideal gas relation: $p_{f i n}=\rho_{f i n} \frac{R}{W} T_{f i n}$.

\subsection{Results of the Lumped Parameter model}

First of all, we shall limit the range of some of our parameters in order to achieve a physically meaningful result i.e. we take a value for the initial hydrogen mole fraction $x_{\mathrm{H}_{2}}^{\text {init }}$ inside the flammability limits and we take a value for the initial water volume fraction $f_{V}$ less or equal to $10^{-3}$ (a value of $f_{V}$ higher or equal to $10^{-2}$ would correspond to more than $10 \mathrm{~kg}$ of liquid water for $1 \mathrm{~kg}$ of ambient gases).

In figure 2, the evolutions of final temperature $T_{\text {fin }}$ as a function of initial mole fraction $x_{H_{2}}^{\text {init }}$ (taken between $8 \%$ and $25 \%$ ) are shown for different values of $f_{V}$. Let us make several observations: 1) in the absence of the liquid water $\left(f_{V}=0\right)$, the final temperature corresponds to the Adiabatic Isochoric Complete Combustion (AICC) temperature, as it should; 2) for a given $x_{\mathrm{H}_{2}}^{\text {init }}$ the temperature decreases with increasing $f_{V}$ i.e. more energy is spent into heating and evaporating a bigger amount of liquid water, and 3) the linear evolution of the final temperature versus the initial mole fraction of hydrogen $x_{H_{2}}^{i n i t}$ is observed for all cases. However, the temperature drop due to the interaction between the flame and the water droplets is more pronounced at low initial hydrogen mole fraction than at higher mole 
fraction; moreover, the effect of the initial water volume fraction $f_{V}$ on the final temperature $T_{\text {fin }}$ decreases as $x_{H_{2}}^{\text {init }}$ increases.

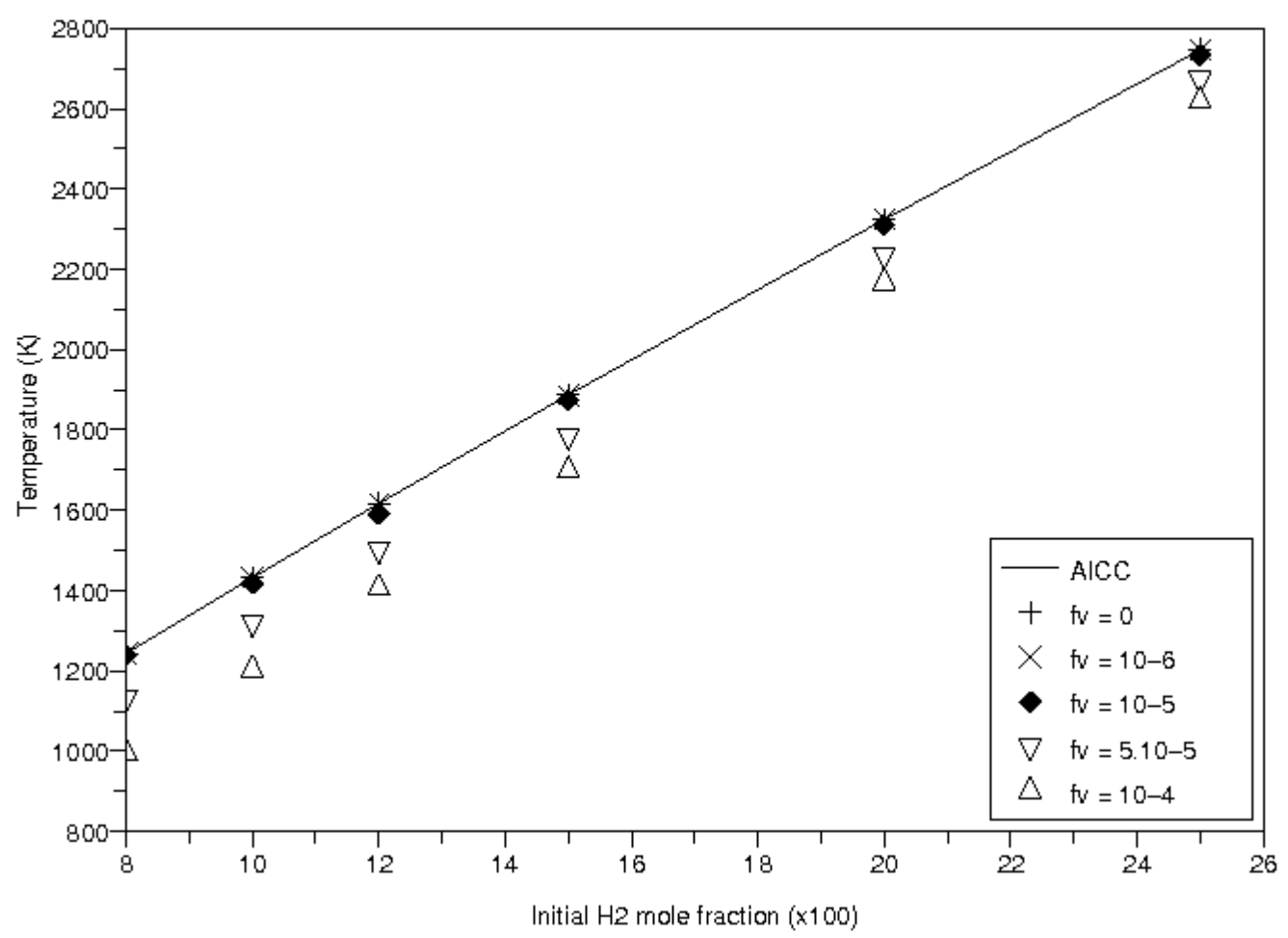

Figure 2. Evolutions of final temperatures as a function of the mole fraction $x_{\mathrm{H}_{2}}^{\text {init }}$ for different initial volume fractions of liquid water $f_{V}$

The evolution of the final pressure (figure 3 ) is nevertheless unexpected. We observe that all pressure curves join in a zone that corresponds to $x_{\mathrm{H}_{2}}^{\text {init }}$ between $8 \%$ and $12 \%$. Beyond this critical zone the pressures are higher than the AICC pressure. Hence we assume that the steam pressure due to water vaporization becomes important as $x_{H_{2}}^{\text {init }}$ increases. In the critical zone, the corresponding final pressure is nearly equal to the AICC pressure. We have for all $f_{V}$ :

$p_{\text {AICC }} \approx p_{f_{V}}$ i.e.

$p_{H 2}^{A I C C}+p_{O 2}^{A I C C}+p_{N 2}^{A I C C}+p_{H 2 O^{c o m b}}^{A I C C} \approx p_{H 2}^{f_{v}}+p_{O 2}^{f_{v}}+p_{N 2}^{f_{v}}+p_{H 2 O^{c o m b}}^{f_{v}}+p_{H 2 O^{e v a p}}^{f_{v}}$, then

$p_{\text {tot }}\left(x_{H 2}^{A I C C}+x_{O 2}^{A I C C}+x_{N 2}^{A I C C}+x_{H 2 O^{\text {comb }}}^{A I C C}\right) \approx p_{\text {tot }}\left(x_{H 2}^{f_{v}}+x_{O 2}^{f_{v}}+x_{N 2}^{f_{v}}+x_{H 2 O^{\text {comb }}}^{f_{v}}+x_{H 2 O^{\text {evap }}}^{f_{v}}\right)$ hence

$A=\left(x_{H 2}^{A I C C}-x_{H 2}^{f_{v}}\right)+\left(x_{O 2}^{A I C C}-x_{O 2}^{f_{v}}\right)+\left(x_{N 2}^{A I C C}-x_{N 2}^{f_{v}}\right)+\left(x_{H 2 O^{c o m b}}^{A I C C}-x_{H 2 O^{c o m b}}^{f_{v}}\right) \approx x_{H 2 O^{\text {evap }}}^{f_{v}}$. 
The table 1 compares the mole fractions of the involved species for the AICC and the $f_{V}=10^{-4}$ case, for two initial hydrogen mole fractions of $8 \%$ and $12 \%$. This table shows that for $x_{\mathrm{H}_{2}}^{\text {init }}=8 \%$, the value of the term $\mathrm{A}$ is 0.1639349 and the difference between the vaporized mole fraction $x_{H 2 O^{\text {evap }}}^{f_{v}=10-4}$ and $A$ is negative. For $x_{H_{2}}^{\text {init }}=12 \%$, this difference is now positive. This proves that the steam pressure due to vaporization becomes important when $x_{H_{2}}^{\text {init }}$ is larger than some critical value.

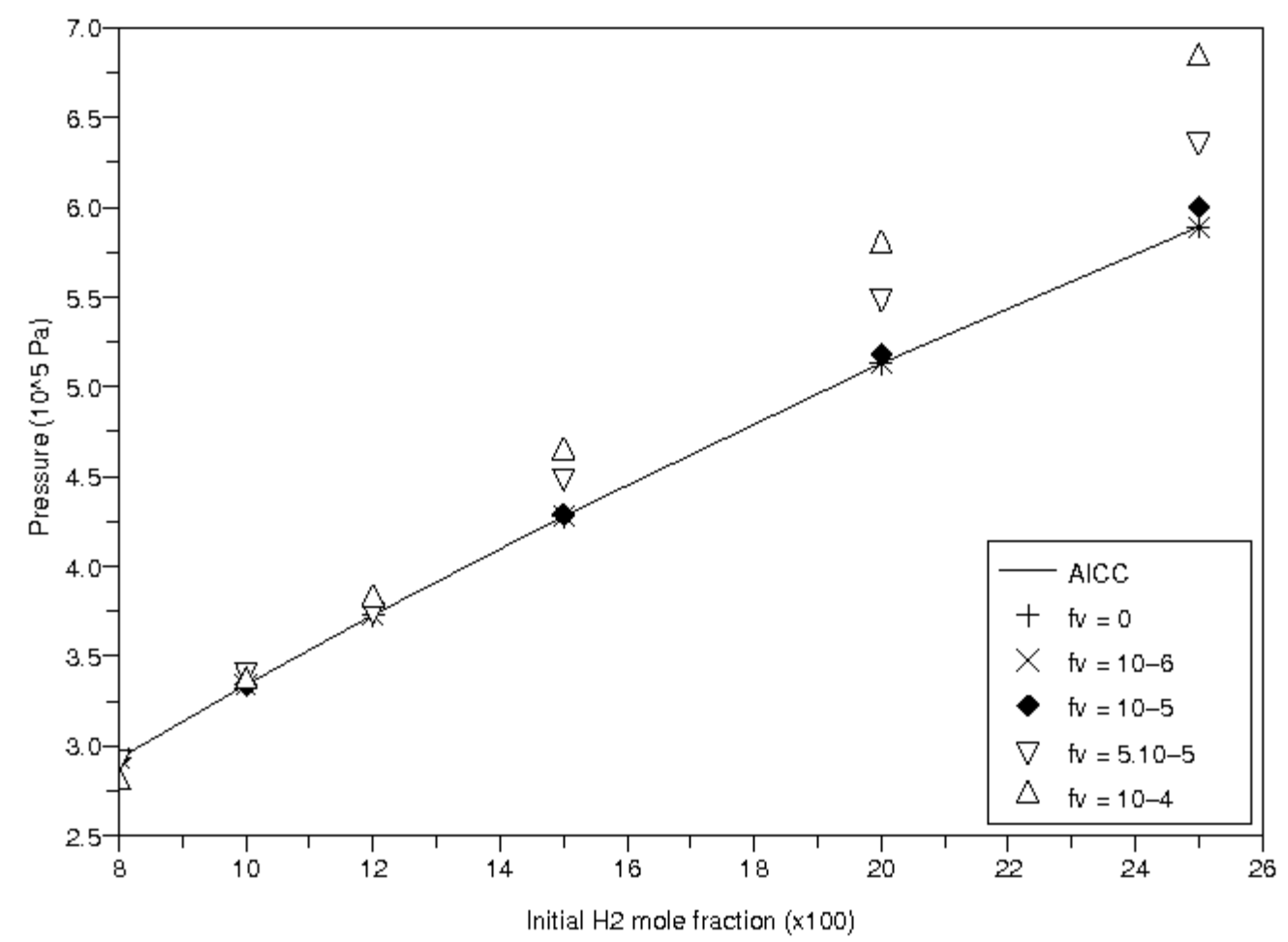

Figure 3. Evolutions of final pressures as a function of the mole fraction $x_{H_{2}}^{\text {init }}$ for different initial volume fractions of liquid water $f_{V}$

\begin{tabular}{|c|c|c|c|c|c|c|}
\hline & $\left(x_{H_{2}}^{\text {init }}=8 \%\right)$ & AICC & $f_{V}=10^{-4}$ & $\left(x_{H_{2}}^{\text {init }}=12 \%\right)$ & AICC & $f_{V}=10^{-4}$ \\
\hline$x_{N_{2}}^{f i n}$ & & 0.7570823 & 0.6329701 & & 0.7395743 & 0.6161823 \\
\hline$x_{\mathrm{O}_{2}}^{f i n}$ & & 0.1595832 & 0.1334219 & & 0.1327670 & 0.1106159 \\
\hline$x_{\mathrm{H}_{2} \mathrm{O}^{\text {comb }}}^{\text {fin }}$ & & 0.0833345 & 0.0696731 & & 0.1276623 & 0.1063629 \\
\hline$x_{H_{2}}^{f i n}$ & & 0.0 & 0.1639290 & & 0.0 & 0.1668460 \\
\hline
\end{tabular}

Table 1. Comparison of the mole fractions of species after combustion for $x_{H_{2}}^{i n i t}=8 \%$ and $x_{H_{2}}^{i n i t}=12 \%$ 
The final density (figure 4) as a function of $x_{\mathrm{H}_{2}}^{\text {init }}$ decreases: 1) as $f_{V}$ increases for a fixed value of $x_{\mathrm{H}_{2}}^{\text {init }}$, the final density $\rho_{\text {fin }}$ increases, and 2) for fixed $f_{V}$ and increasing $x_{H_{2}}^{i n i t}$, we expect that $\rho_{\text {fin }}$ decreases.

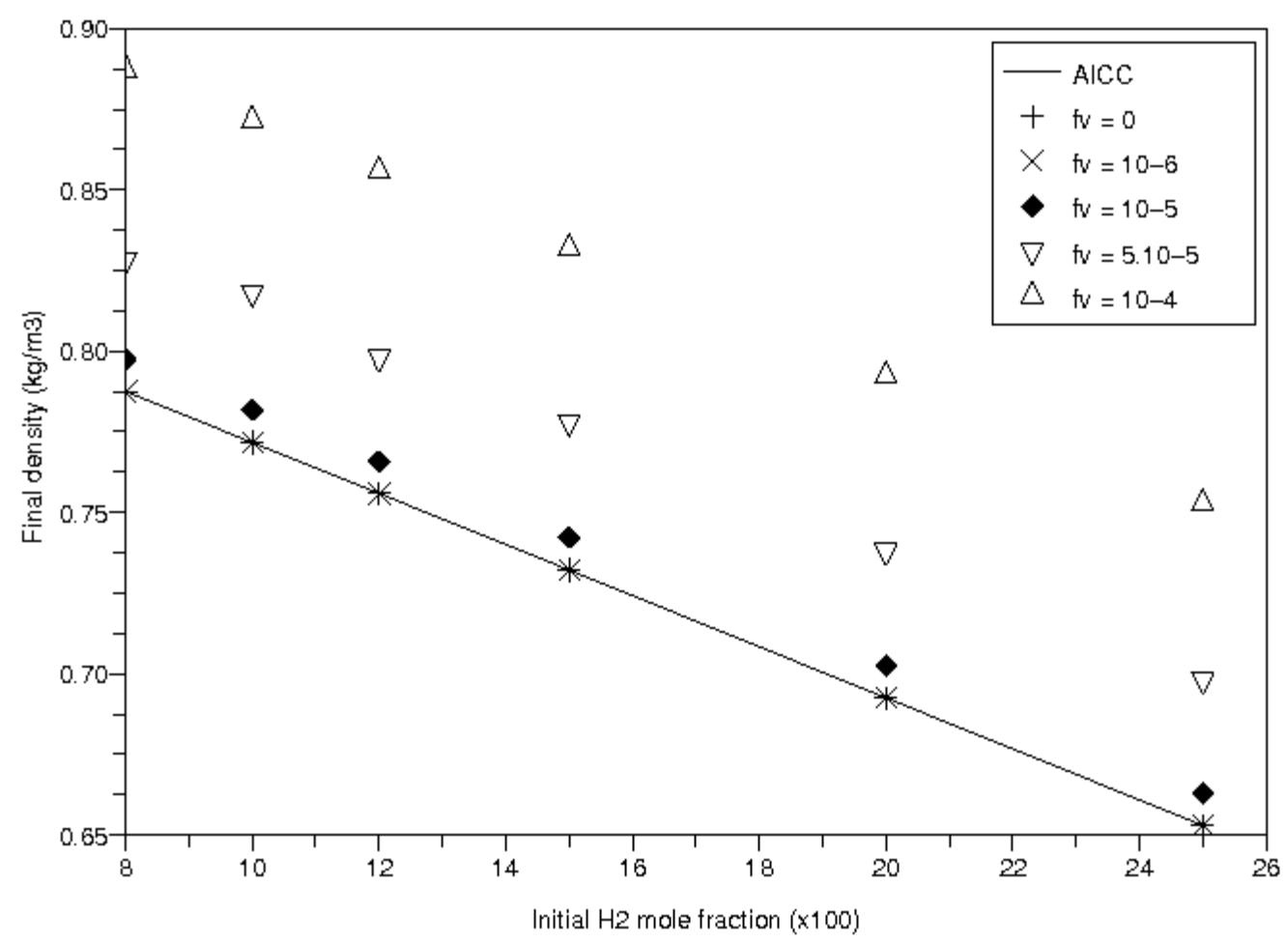

Figure 4. Evolution of the final density as a function of $x_{\text {init }}^{H 2}$ for different initial volume fractions of liquid water $f_{V}$

This first study improves our knowledge about the thermodynamic effects involved during the interaction of a water spray and a hydrogen-air flame. A CFD study is the next step of this work and is in progress. Experimental data to validate both Lumped Parameter and CFD models are however necessary. This is the object of the following section.

\section{Experimental study: expanding spherical flames in water mist}

A new experimental set-up has been designed in the laboratory ICARE-CNRS $[18,19]$ and is described in this paper. The spray system and the first results on the characteristics of the spray will be also presented.

\subsection{Experimental set-up}

The bomb is a stainless steel sphere (i.d. $476 \mathrm{~mm}$ ) equipped with 4 opposite quartz windows $(100 \mathrm{~mm}$ optical diameter, $40 \mathrm{~mm}$ thick); it has a black polished surface in order to suppress multiple diffusion (figure 5). Two tungsten electrodes (diameter $2 \mathrm{~mm}$ ), located along a diameter of the sphere, are 
linked to a high voltage source (about $10 \mathrm{kV}$ ). The gap between the electrodes is adjustable and is usually fixed around $1 \mathrm{~mm}$. Ignition was produced at the centre of the sphere. The voltage and intensity discharge were measured with a high voltage probe and a current probe (figure 6).

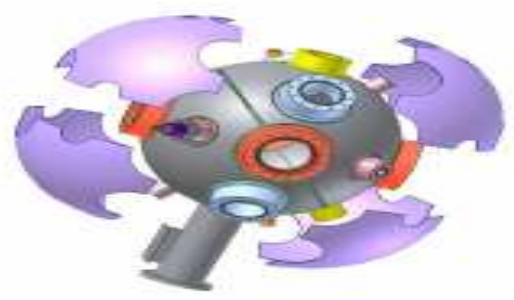

Figure 5. Schematic of the spherical bomb.

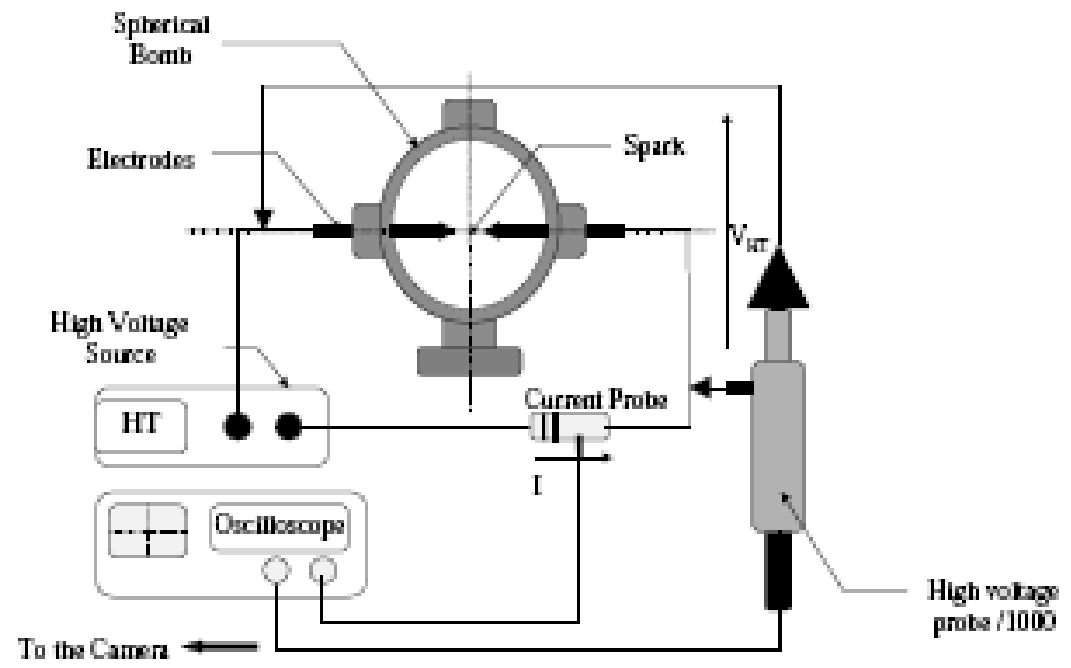

Figure 6. Schematic of the ignition device and the voltage and current probes.

As far as hydrogen is concerned, the visualization of the flame is obtained via the classical Schlieren apparatus. It consists of 2 concave spherical mirrors ( $80 \mathrm{~mm}$ diameter and $1 \mathrm{~m}$ focal length), the source light is a continuous argon ion laser, the laser beam is focused via 2 lenses (diam. $75 \mathrm{~mm}$ and $20 \mathrm{~mm}$ with $150 \mathrm{~mm}$ and $22 \mathrm{~mm}$ focal lengths respectively). A numerical high speed camera (FASTCAM APX) with an acquisition frequency up to 120000 images per second was used to register the schlieren images of the expanding flame. The images are processed (Visilog 5.2 image processing) in order to derive the radius of the flame in function of time.

\subsection{Spray system}

The spherical bomb is equipped with different nozzles in order to inject a spray of water inside the bomb prior to ignition or during the flame propagation. To do so, two different nozzles were used and 
characterized. The first one is a mono-fluid nozzle (SS-LNND-0.60 from Spraying Systems), the water was fed to the nozzle at different initial pressures (between 7 and 50 bars). The size distribution according to the water pressure was measured using a real-time measurements sizer based on the laser light diffraction. As it is shown in figure 7, the size distribution is shifted towards lower value as the pressure of water is increased. The Sauter diameter decreases from $60 \mu \mathrm{m}$ at 5 bars to $33 \mu \mathrm{m}$ at 50 bars.

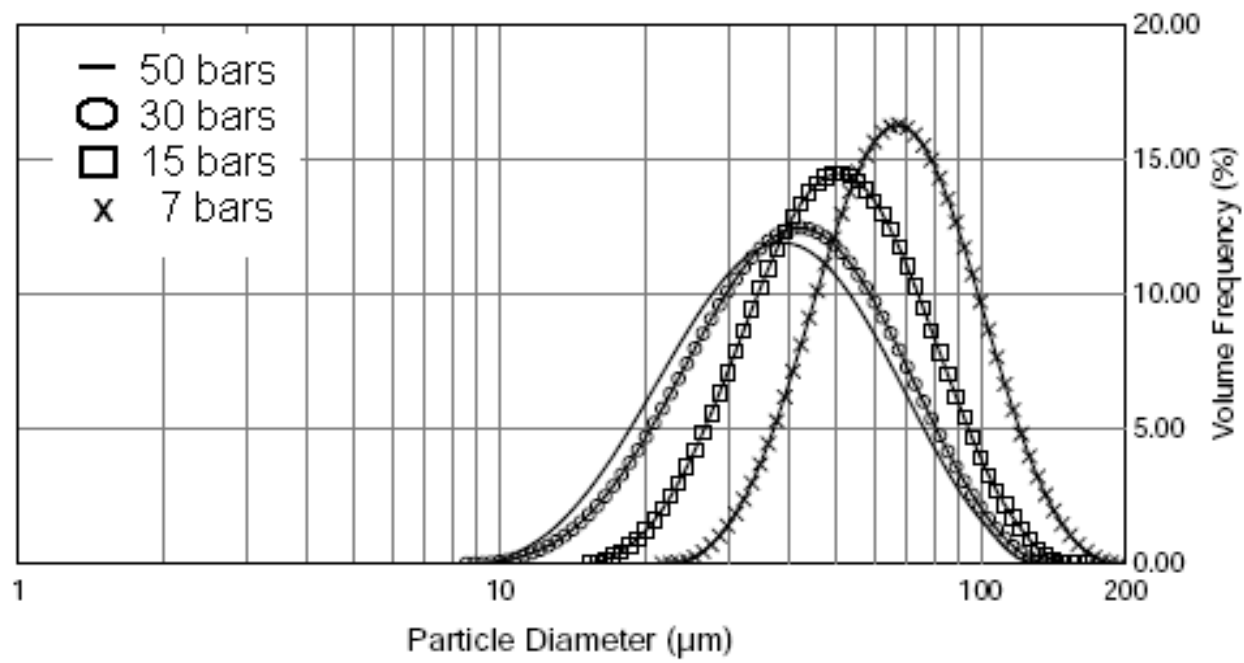

Figure 7. Spray size distribution according to the water pressure using a mono-fluid nozzle.

The second type of nozzle that was characterized is a bi-fluid from Spraying Systems (LNND-SU1A 1650). In this case water was entrained using compressed air at different pressures. The sprays obtained in this configuration were characterized using the same sizer. The main results are summarized in figure 8 .

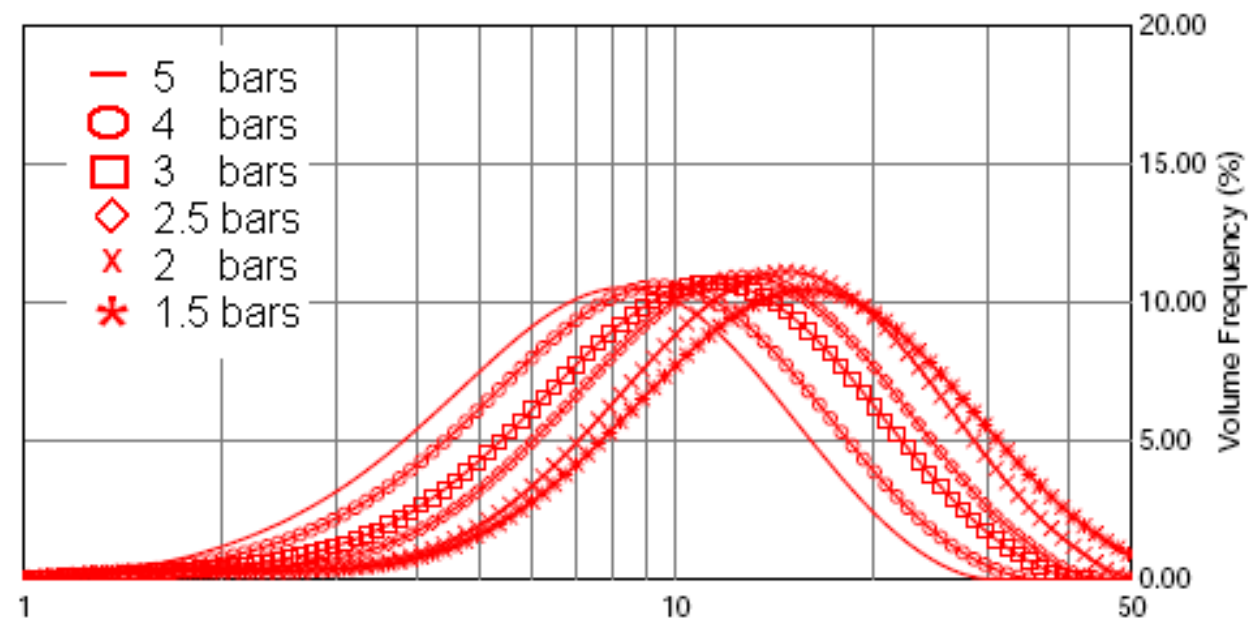

Particle Diameter $(\mu \mathrm{m})$

Figure 8. Spray size distribution according to the water pressure using a bi-fluid nozzle. 
As it can be seen from figure 8, in the case of a bi-fluid nozzle, the effect of the pressure is limited on the size distribution. The mean Sauter diameter decreases from $11.5 \mu \mathrm{m}$ down to $6 \mu \mathrm{m}$ as the pressure is raised from 1.5 up to 5 bars.

\section{Concluding remarks}

The Lumped Parameter analysis simply gives us the final pressure and temperature in case of an accidental hydrogen-air flame under water spray conditions. It has shown that liquid water generates heat sink as expected. It has also highlighted that the steam due to water vaporization becomes important as the amount of initial hydrogen attains a certain value (between $8 \mathrm{~mol} \%$ and $12 \mathrm{~mol} \%$ with our data) so that the final pressures are higher than the AICC pressure. This work is currently being completed by a full CFD modeling taking into account the reaction rate and a polydisperse spray in order to obtain the evolutions of pressure and temperature between the initial state and the final one. The first part of the experimental study was devoted to characterize the spray in terms of size distribution before coupling the combustion with the spray.

\section{Acknowledgements}

The authors wish to thank Etienne Studer, Henri Paillère, Sergey Kudriakov and Alberto Beccantini from CEA, Christophe Proust from INERIS, Ahmed Bentaïb from IRSN, Claude Paillard from ICARE-CNRS and Christophe Corre from LEGI-CNRS for their support.

\section{References}

1. Kitagawa T, Nakahara T, Maruyama K, Kado K, Hayakawa A, Kobayashi S. Turbulent burning velocity of hydrogen-air premixed propagating flames at elevated pressures. International Journal of Hydrogen Energy 2008; 33(20):5842-5849.

2. Tang C, Huang Z, Jin C, He J, Wang J, Wang X, Miao H. Explosion characteristics of hydrogennitrogen-air mixtures at elevated pressures and temperatures. International Journal of Hydrogen Energy 2009; 34(1):554-561.

3. Kudriakov S, Dabbene F, Studer E, Beccantini A, Magnaud JP, Paillère H, Bentaïb A, Bleyer A, Malet J, Porcheron E, Caroli C. The TONUS CFD code for hydrogen risk analysis: Physical models, numerical schemes and validation matrix. Nuclear Engineering and Design 2008; 238(3): 551-565.

4. Parra T, Castro F, Méndez C, Villafruela JM, Rodrìguez MA. Extinction of premixed methane-air flames by water mist. Fire Safety Journal 2004; 39:581-600.

5. Prasad K, Li C, Kailasanath K. Simulation of water mist suppression of small scale methanol liquid pool fires. Fire Safety Journal 1999; 33:185-212.

6. Downie B, Polymeropoulos C, Gogos G. Interaction of a water Mist with a Buoyant Methane Diffusion Flame. Fire Safety Journal 1995; 24:359-381.

7. Modak AU, Abbud-Madrid A, Delplanque J-P, Kee RJ. The Effect of monodispersed water mist on the suppression of laminar premixed hydrogen-, methane-, and propane-air flames. Combustion and Flame 2006; 144:103-111.

8. Prasad K, Patnaik G, Kailasanath K. A numerical study of water-mist suppression of large scale compartment fires. Fire Safety Journal 2002; 37:569-589.

9. Jones SJ, Averill AF, Ingram JM, Holborn PG, Battersby P, Nolan PF, Kempsell ID, Wakem MJ. Mitigation of hydrogen-air explosions using fine water mist sprays. In: Symposium series NO. 151. IChemE, 2006.

10. Yang W, Kee RJ. The Effect of Monodispersed WaterMists on the Structure, Burning velocity, and Extinction behavior of Freely Propagating, Stoichiometric, Premixed, methane-Air Flames. Combustion and Flame 2002; 130:322-335. 
11. Thomas GO. On the conditions required for explosion mitigation by water sprays. Trans I Chem E: Part B - Process Safety and Environmental Protection 2000; 78:339-354.

12. van Wingerden $\mathrm{K}$, Wilkins $\mathrm{B}$. The influence of water sprays on gas explosions. Part II: mitigation. Journal of Loss Prevention in the Process Industries 1995; 8(2):61-70.

13. Lentati AM, Chelliah HK. Dynamics of Water Droplets in a Counterflow Field and their Effect on Flame Extinction. Combustion and Flame 1998; 115:158-179.

14. Proust C. Flame-water droplets interactions. 1996.

15. Mitani T. A flame inhibition theory by inert dust and spray. Combustion and Flame 1981; 43:243253.

16. van Wingerden K, Wilkins B. The influence of water sprays on gas explosions. Part I: water spray-generated turbulence. Journal of Loss Prevention in the Process Industries 1995; 8(2):53-59.

17. Kee RJ, Rupley FM, Miller JM. The CHEMKIN Thermodynamic Data Base. Technical Report SAND87-8215B, SANDIA, 1987.

18. Lamoureux N, Djebaïli-Chaumeix N, Paillard CE. Laminar flame velocity determination for $\mathrm{H}_{2}-$ air-He- $\mathrm{CO}_{2}$ mixtures using the spherical bomb method. Experimental Thermal and Fluid Science 2003; 27:385-393.

19. Lamoureux N, Malet F, Djebaïli-Chaumeix N, Bentaïb A, Bleyer A, Paillard CE. H2 Gradient Effect on Premixed Flame Propagation in a Vertical Facility: ENACCEF, Proceedings of the 20th International Colloquium on the Dynamics of Explosions and Reactive Systems, Montréal, Canada, 2005. 